\title{
FORECASTING EXCHANGE RATES AND RELATIVE PRICES WITH THE HAMBURGER STANDARD: IS WHAT YOU WANT WHAT YOU GET WITH MCPARITY?
}

Robert E. Cumby

NBER Working Paper 5675

\section{NATIONAL BUREAU OF ECONOMIC RESEARCH 1050 Massachusetts Avenue Cambridge, MA 02138 \\ July 1996}

This paper is part of NBER's research program in International Finance and Macroeconomics. Any opinions expressed are those of the author and not those of the National Bureau of Economic Research.

(C) 1996 by Robert E. Cumby. All rights reserved. Short sections of text, not to exceed two paragraphs, may be quoted without explicit permission provided that full credit, including $\odot$ notice, is given to the source. 


\title{
FORECASTING EXCHANGE RATES AND \\ RELATIVE PRICES WITH THE HAMBURGER \\ STANDARD: IS WHAT YOU WANT WHAT \\ YOU GET WITH MCPARITY?
}

\begin{abstract}
A decade ago the Economist began an annual survey of Big Mac prices as a guide to "whether currencies are trading at the right exchange rates." This paper asks how well the hamburger standard has performed. Although average deviations from absolute Big Mac parity are large for several currencies, once estimates of these average deviations are removed from the data, the evidence suggests that convergence to relative Big Mac parity is quite rapid. The half-life of deviations from Big Mac parity appear to be about 1 year, which is considerably shorter than estimates of the half-life of deviations from purchasing power parity (4-5 years) that are reported in the literature. In addition, deviations from relative Big Mac parity appear to provide useful information for forecasting exchange rates. After accounting for currency-specific constants, a 10 percent undervaluation according to the hamburger standard in one year is associated with a 3.5 percent appreciation over the following year. Finally, deviations from relative Big Mac parity seem to be helpful in forecasting relative local currency prices. When the U.S. dollar price of Big Macs is high in a country, the relative local currency price of Big Macs in that country is likely to fall during the following year.
\end{abstract}

Robert E. Cumby Department of Economics Georgetown University Washington, DC 20057 and NBER 
In 1986 the Economist began publishing a survey of prices of Big Macs in a number of countries as a rough (or as they characterized it, a "medium rare") guide to "whether currencies are trading at the right exchange rates." It seems natural to examine how the hamburger standard has performed.

A casual reader of the Economist knows that deviations from Big Mac parity in any given year can be sizable. But if those deviations tend to die out quickly, the hamburger standard may provide a useful guide to underlying currency values. In this paper I ask three questions about the behavior of deviations from Big Mac parity. First, are deviations from Big Mac parity permanent or is there a tendency toward a return to Big Mac parity? If there is a tendency toward Big Mac parity, what is the nature of the adjustment? If part of the adjustment comes through exchange rate changes, deviations from Big Mac parity might be useful in forecasting exchange rate changes. This raises the second question. Do current deviations from Big Mac parity help forecast future exchange rate changes? A tendency toward Big Mac parity may also arise if deviations influence local currency pricing decisions. If current deviations from Big Mac parity influence local currency pricing decisions, current deviations should help predict future relative price changes. This suggests a third question. Do deviations from Big Mac parity forecast changes in the relative local currency prices of Big Macs?

When using the hamburger standard data to answer questions about the dynamics of deviations from Big Mac parity and the usefulness of these deviations in forecasting future exchange rate and relative price changes, one is inevitably confronted with the relatively short time series available. These short time series make it difficult to draw conclusions about the

${ }^{1}$ Economist, September 6, 1986, p.77. 
dynamic behavior of deviations from Big Mac parity and the forecasting power of these deviations. I attempt to overcome the difficulties raised by the short sample by exploiting the panel aspect of the data. Although the Economist has published data for only a relative short period of time, it provides similar data for a number of currencies. This yields a substantially larger data set for inference and facilitates more precise estimates of the dynamic relationship followed by exchange rate changes and deviations from Big Mac parity than is possible using only time series evidence.

\section{Data}

The Economist introduced its annual survey of the "hamburger standard" in its September 6, 1986 issue with data submitted by its "Golden Arches" correspondents. The initial piece contained price data on Big Macs from fifteen countries along with the corresponding fourteen exchange rates relative to the U.S. dollar. They followed this piece in the January 12, 1987 issue with price data from nine countries, seven of which were included in the September 1986 survey. Denmark and Italy were added. The survey has been repeated annually in April from 1988 through 1996 with its coverage expanded from seventeen countries in 1988 to thirty-three countries in 1996.

Because the 1986 and 1987 surveys were much closer together than the subsequent surveys (one quarter rather than one year apart) and the coverage of the 1987 survey is much narrower than the others, I combine the two by taking the 1987 data when available and the 1986 data otherwise. Over time countries have been added to the survey and some have been dropped. 
The sample I use consists of the fourteen countries that have the full ten years of data. ${ }^{2}$ I then have a panel consisting of thirteen exchange rates and ten time series observations. One observation is lost because a lag is needed for the regressions, so there are effectively nine time series observations for each currency.

I. The Dynamics of Deviations from Big Mac Parity

Let $E_{i, t}$ be the exchange rate between currency $i$ and the U.S. dollar at time $t$, expressed as units of currency i per U.S. dollar. Next, let $P_{i, t}$ be the local currency price of a Big Mac. Define the Big Mac parity exchange rate, $\mathrm{EBMP}_{\mathrm{i}, \mathrm{t}}$, between currency $i$ and the U.S. dollar as the exchange rate that equates the U.S. dollar price of Big Macs in country $i$ with the U.S. price of Big Macs. Thus, $\mathrm{EBMP}_{\mathrm{i}, \mathrm{t}}=\mathbf{P}_{\mathrm{i}, \mathrm{f}} / \mathbf{P}_{\mathrm{Us}, \mathrm{t}}$ and $\mathrm{q}_{\mathrm{i}, \mathrm{t}}=\ln \left(\mathrm{EBMP}_{\mathrm{i}, \mathrm{E}} / \mathrm{E}_{\mathrm{i}, \mathrm{t}}\right)$ is approximately the percent deviation from Big Mac parity. Equivalently, $\ln \left(\mathrm{EBMP}_{\mathrm{i},} / \mathrm{E}_{\mathrm{i}, \mathrm{t}}\right)$ is the logarithm of the real Big Mac exchange rate.

Standard augmented Dickey-Fuller (1979) tests for the stationarity of deviations from Big Mac parity are based on the autoregression,

$$
\Delta q_{i, t}=\theta_{i}+\left(\rho_{i}-1\right) q_{i, t-1}+\sum_{j=1}^{k_{i}} \gamma_{i j} \Delta q_{i, t-j}+v_{i, t^{*}}
$$

Unfortunately these test have notoriously low power, a problem that is likely to be especially severe a sample of 10 annual observations. The panel nature of the data may, however, allow for

${ }^{2}$ These countries are, Australia, Belgium, Britain, Canada, Denmark, France, Germany, Holland, Hong Kong, Italy, Japan, Spain, Sweden, and the United States. 
greater power. Im, Pesaran and Shin (1995) propose a test for unit roots in a heterogenous panel. Their test of the null hypothesis that $\rho_{i}=1$ for $\mathrm{i}=1, \ldots, \mathrm{N}$ is based on the average t-ratio from (1), $\bar{t}_{N}=N^{-1} \Sigma_{i=1}^{N}\left(\hat{\rho}_{i}-1\right) / \hat{\sigma}_{p}$. They show that the statistic,

$$
\mathrm{z}_{\mathrm{N}, \mathrm{T}}=\sqrt{\mathrm{N}}\left(\frac{\overline{\mathrm{t}}_{\mathrm{N}}-\mathrm{a}_{\mathrm{T}}}{\sqrt{\mathrm{b}_{\mathrm{T}}}}\right)
$$

is distributed asymptotically as a standard normal. The mean and variance of the average t-ratio, $a_{T}$ and $b_{T}$ depend only on $T$ and $\vec{k}$ (the average of the $k_{i}$ ) and are tabulated by Im, Pesaran, and Shin. ${ }^{3}$

The results of the augmented Dickey-Fuller and Im, Pesaran, and Shin tests are reported in Table 1. The first column contains the sample means of the deviations from Big Mac parity, the second and third columns report the estimates of the intercept and the autoregressive coefficient, $\rho$, computed with $k_{i}$ set to zero. The fourth column contain the augmented Dickey-Fuller t-ratio computed with the number of lags, $k_{i}$ (reported in column 5), determined using the general-tospecific procedures suggested by Hall (1994) and Ng and Perron (1995). The estimates of the autoregressive coefficient are all far from one. In fact, none is significantly different from zero at conventional levels. But, due to the small sample and the consequent lack of precision in estimating $\rho$, only four of the augmented Dickey Fuller tests point to a rejection of the null

${ }^{3}$ The asymptotic distribution is obtained by letting $\mathrm{N} \rightarrow \infty, \mathrm{T} \rightarrow \infty$, and $\mathrm{N} / \mathrm{T} \rightarrow \infty$ and assuming that the data are generated independently across $\mathrm{i}$. They suggest taking out common time effects by using time dummies or (equivalently) computing the test statistics using deviations from cross section means to account for correlation across cross section units. 
hypothesis that $\rho=1.0{ }^{4}$ The greater power derived from exploiting the panel aspect of the data is apparent in the results of the Im, Pesaran, and Shin tests, which yield standard normal statistics around four both with and without common time dummies. ${ }^{5}$

The results in Table 1 clearly indicate that deviations from Big Mac parity are transitory, but the estimates of $\rho$ are too imprecise to get a clear idea of rate of convergence. In order to get a better estimate of the dynamics of deviations from Big Mac parity I next pool the data and estimate the regression,

$$
\ln \left(\frac{\mathbf{E B M P}_{\mathrm{i}, \mathrm{t}}}{\mathrm{E}_{\mathrm{i}, \mathrm{t}}}\right)=\theta+\rho \ln \left(\frac{\mathrm{EBMP}_{\mathrm{i}, \mathrm{t}-1}}{\mathrm{E}_{\mathrm{i}, \mathrm{t}-1}}\right)+\mathbf{u}_{\mathrm{i}, \mathrm{t}}
$$

If ordinary least squares is to yield valid inference, the errors in (2) must be uncorrelated across currencies. This is unlikely to be the case since some shocks are likely to affect all exchange rates relative to the U.S. dollar. As a result, the covariance matrix obtained from ordinary least squares will not be correct. In order to remove these aggregate shocks and obtain valid inference, I include time dummies common to each currency in the regression. By using the time dummies, I separate the innovations for each period into a common component and orthogonal currency-specific components. The common component is estimated as the coefficients on the dummy variables. The resulting currency-specific forecast errors will have mean zero and will mutually uncorrelated. The model then becomes,

${ }^{4}$ In only one instance, Spain, is the number of lags nonzero. Although the null of $\rho=1.0$ is rejected in this instance, the estimate is unreliable as the regression with two lags has only three degrees of freedom. The Dickey Fuller t-ratio for Spain with $k$ set to zero is -1.752 .

${ }^{5}$ When the number of lags is set to zero for Spain, the Im, Pesaran, and Shin statistics are about -3.5 and therefore still strongly reject the null hypothesis of a unit root. 


$$
\ln \left(\frac{\text { EBMP }_{i, t}}{E_{i, t}}\right)=\theta+\lambda_{t}+\rho \ln \left(\frac{\text { EBMP }_{i, t-1}}{E_{i, t}}\right)+u_{i, t} \cdot
$$

Another problem with ordinary least squares estimation of the pooled model is that there may be persistent, currency-specific effects. Because Big Mac production and sale involves inputs of nontraded goods and domestic labor, differences in, for example, per capita income may lead to persistent deviations from Big Mac parity. In addition, trade barriers and difference in indirect taxes will also lead to persistent deviations from Big Mac parity. ${ }^{6}$ This concern that persistent currency-specific effects might be important is reinforced by wide range of intercepts reported in Table 1 and the extensive variation in sample average deviations.

Adding currency-specific intercepts, the model becomes,

$$
\ln \left(\frac{\text { EBMP }_{\mathrm{i}, \mathrm{t}}}{\mathrm{E}_{\mathrm{i}, \mathrm{t}}}\right)=\theta_{\mathrm{i}}+\lambda_{\mathrm{t}}+\rho \ln \left(\frac{\mathrm{EBMP}_{\mathrm{i}, \mathrm{t}-1}}{\mathrm{E}_{\mathrm{i}, \mathrm{t}}}\right)+\mathrm{u}_{\mathrm{i}, \mathrm{t}} .
$$

The standard fixed-effects estimator, which is the ordinary least squares estimate of (4), is biased downward in dynamic panels. Although the bias goes to zero as $\mathrm{T} \rightarrow \infty$, it can be substantial when $\mathrm{T}$ is small. Fortunately for the simple autoregressive model considered here, Nickell (1981) has computed bias analytically for large $\mathrm{N}$ and the bias has a particularly simple form.

$$
\underset{N \rightarrow \infty}{\operatorname{plim}(\hat{\rho}-\rho)}=-\frac{1+\rho}{T-1}\left(1-\frac{1-\rho^{T}}{T(1-\rho)}\right)\left(1-\frac{2 \rho}{(1-\rho)(T-1)}\left[1-\frac{1-\rho^{T}}{T(1-\rho)}\right]\right)
$$

An alternative is to take first differences to remove the intercepts. The model then

${ }^{6}$ Pakko and Pollard (1996) point to several examples and the Economist, April 27, 1996 notes that high rates of value-added taxation in Sweden and Denmark raise the price of Big Macs and, therefore, the Big Mac parity exchange rate for those two currencies. 
becomes,

$$
q_{i, t}-q_{i, t-1}=\rho\left(q_{i, t-1}-q_{i, t-2}\right)+\lambda_{t}-\lambda_{t-1}+u_{i, t}-u_{i, t-1} .
$$

Because the regressor is a lagged endogenous variable, first differencing induces correlation between $u_{i, t-1}$ and $q_{i, t-1}$ and an instumental variables estimator is required to obtain consistent estimates. In addition, as is clear from (5), the error is a first-order moving average. On the basis of a wide range of Monte Carlo experiments, Kiviet (1995) argues that instrumental variables estimators of first-differenced fixed-effects models have considerable dispersion. He concluses that the finite sample properties of bias-corrected the least squares with dummy variables estimator are superior to those of instrumental variables estimators. I therefore focus on the least squares estimates of (2), (3), and (4). ${ }^{7}$

The results of the pooled estimates are reported in Table $2 .^{8}$ The simple pooled estimate (with no time or currency dummies) suggests that convergence to Big Mac parity is quite slow. Only about 10 percent of a deviation is eroded each year so that the half life of a deviation from Big Mac parity is nearly seven years. The estimated rate of convergence slows when common time dummies are added. The size of the difference between these two pooled estimates of the rate of convergence and the estimates of the country-specific autoregressive coefficients in Table

${ }^{7}$ As Kiviet's Monte Carlo evidence would suggest, instrumental variables estimation of (5) yields standard errors that are so large that no meaningful hypothesis can be rejected. The problems with instrument variables estimates are almost certainly aggrevated by the small $\mathrm{N}$ in this sample.

${ }^{8}$ I report both ordinary least squares estimates (with a heteroskedasticity consistent standard error) and weight least squares estimates based on the residual variances for each of the countries. Because $k_{i}=0$ in the augmented Dickey-Fuller tests, I make no correction for serial correlation. 
2 raises serious questions. These questions are resolved when the fixed effects model (including both time dummies and currency dummies) is estimated. The estimated value of $\rho$ drops dramatically to 0.275 .

The difference between the simple pooled and fixed effects estimates of the autoregressive parameter is illustrated in Figure 1 where I plot the current deviation from Big Mac Parity against the lagged deviation for four currencies. As is reflected in the regression results, pooling the deviations across currencies without taking account of currency-specific means yields a much higher estimate of the autoregressive coefficient than is characteristic of any one of the currencies. 9

This fixed effects estimate overstates the rate of convergence because of the downward bias in the fixed effects estimate of $\rho$. For a sample size of 9 observations and a true value of $\rho$ of 0.45 , for large $\mathbf{N}$, the least squares estimate of $\rho$ tends toward 0.277 . Thus the fixed effects estimates are consistent with an autoregressive coefficient around 0.45 and a half-life of deviations from Big Mac parity of just under one year. This is considerably shorter than the 4 to 5 years found by Lothian (1994) and Frankel and Rose (1995) using aggregate price levels and by and Wei and Parsley (1994) using sectoral prices.

But these calculations are valid for large $\mathrm{N}$ and, in this sample, $\mathrm{N}$ is only 13 . In order to determine the magnitude of the bias for a sample with $\mathrm{N}=13$ and $\mathrm{T}=9$, I perform Monte Carlo experiments by generating 1000 replications of panels with a true value of $\rho=0.45$ and with

${ }^{9}$ The figure also shows that the negative estimate $\rho$ for Hong Kong is due to an outlier. This outlier arises because of a somewhat anomalous price reported for Big Macs in the United States in 1988. The effect of this price is common to the deviations for all currencies and is thus removed by the common time dummies. 
intercepts equal to the mean deviations from Big Mac parity reported in Table 1 . The mean estimate of $\rho$ from these experiments is 0.274 . This estimate of the bias in the fixed effects estimator differs from its large- $\mathrm{N}$ value only in the third decimal place.

One puzzle remains. The bias-adjusted fixed effects estimate of the autoregressive parameter exceeds the estimates from the currency-specific autoregressions reported in Table 1. In fact, even the unadjusted fixed effects estimate exceeds the average from Table 1. The reason for this difference is that the bias in the autoregressive parameter in a single autoregression is even greater that it is for the fixed effects estimator. Nickell (1981) shows that for reasonably large T, the bias of the fixed effects estimator is approximately $-(1+\rho) /(T-1)$ while the bias for the single autoregression is approximately $-(1+3 p) /(\mathrm{T}-1)$.

\section{The Adjustment of Exchange Rates and Relative Local Currency Prices}

The results discussed in section II suggest that deviations from Big Mac parity are transitory and have a half life of about one year once allowance is made for nonzero mean deviations. Therefore either exchange rates or relative local currency prices must be adjusting toward Big Mac parity. This adjustment implies that current deviations from Big Mac parity should be useful for predicting exchange rate and/or relative local currency price changes over the subsequent year. In this section we examine the value of current deviations from Big Mac parity in forecasting these changes.

The information content of deviations from Big Mac parity for forecasting future exchange rate changes is examined with the regression: 


$$
\ln \left(\frac{E_{i, t}}{E_{i, t-1}}\right)=\delta_{i}+\varphi_{t}+\beta \ln \left(\frac{\text { EBMP }_{i, t-1}}{E_{i, t-1}}\right)+v_{i, t}
$$

If $\beta \neq 0$, deviations from Big Mac parity provide useful information in forecasting exchange rates. In addition to testing the hypothesis that the deviation from Big Mac parity provide no information useful in forecasting exchange rates $(\beta=0)$, it might also be interesting to test whether a currency that is undervalued according to the Big Mac standard (EBMP $\mathrm{it}_{\mathrm{t}-1}<\mathrm{E}_{\mathrm{i},-1-1}$ ) is likely to appreciate between $t-1$ and $t(\beta>0)$ or even whether the appreciation between $t-1$ and $t$ is proportional to the deviation at $\mathrm{t}-1(\beta=1)$.

Table 3 presents the estimates of three versions of $(6)$ : the simple pooled estimates $\left(\delta_{i}=\delta\right.$, $\left.\varphi_{t}=0\right)$, the estimates with time dummies only $\left(\delta_{i}=\delta\right)$, and the fixed effects estimates (with time and currency dummies). ${ }^{10}$ Once again, the importance in taking account of currency specific intercepts is strikingly apparent. When only time dummies are used, the estimates suggest that a currency that is undervalued according to the hamburger standard is likely to appreciate slightly but the point estimates are less than their standard errors. Including currency-specific intercepts raises the slope estimate dramatically and the estimates are highly significant. According to this estimate, a 10 percent undervaluation leads to a 5 percent appreciation in the subsequent year. Although the regressor in (6) is not a lagged left-hand-side variable, it is predetermined

${ }^{10}$ Chamberlain (1984) argues that aggregate shocks may lead to inconsistent estimates in a models like (6) and (7), thereby providing another reason to include time dummies in (6) and (7). In a time series context, ordinary least squares is assumed to lead to consistent estimates in (6) or (7) because the deviation from Big Mac parity at $t-1$ is assumed to be in the t- 1 information set of agents. An assumption of rational expectations is generally used to assume that the error and any variables in the information set have a sample covariance that converges to zero as the number of observations in the time series gets large. The time $t-1$ deviation is therefore uncorrelated with the errors in (6) or (7). In a panel with relatively few time series observations, however, the least squares estimates may be inconsistent. 
rather than exogenous and a small- $\mathrm{T}$ bias in the fixed effects estimator remains a potential problem. Unfortunately, the magnitude of the bias does not have a simple form and I must rely on Monte Carlo evidence to determine the likely magnitude of the bias. I estimate a vector autoregression for exchange rate changes and deviations from Big Mac parity and use the estimates to generate 1,000 panels with $\mathrm{N}=13$ and $\mathrm{T}=9$. I then compute the fixed effects estimator of the slope of a regression of exchange rate changes on lagged deviations from Big Mac parity. In these Monte Carlo experiments the mean estimate of the slope is 0.53 and the "true value" (computed from the VAR parameters) that is used in generating the data is .38. Thus it appears that the fixed effects estimate of the slope of (6) is biased upward by approximately 0.15 . Adjusting the estimates from Table 3 by this estimate of the bias yields a bias-adjusted slope of about 0.35 . After adjusting for the bias then, a 10 percent undervaluation in one year leads to a 3.5 percent appreciation in the subsequent year.

Finally, I ask if current deviations from Big Mac parity are useful in forecasting changes in relative Big Mac prices and estimate the regression,

$$
\ln \left(\frac{\text { EBMP }_{i, t}}{\text { EBMP }_{i, t-1}}\right)=\mu_{i}+\psi_{t}+\pi \ln \left(\frac{\text { EBMP }_{i, t-1}}{E_{i, t-1}}\right)+\eta_{i, t}
$$

If a currency appears to be overvalued according to the hamburger standard (Big Mac prices measured in a common currency are high), the deviation may be subsequently reduced by a decline in the relative local currency prices of Big Macs. If $\pi<0$, current deviations from Big Mac parity are useful in predicting changes in relative local currency prices.

Panel B of Table 3 presents the results for the three versions of (7). In all versions, a deviation from Big Mac parity in one year tends to be reduced by changes in the relative local 
currency prices over the following year. When both time and currency dummies are included, the estimated slope rises sharply in absolute value. The fixed effects estimates suggest that a country in which the currency is overvalued by 10 percent in a given year will tend to experience about a 2 percent decline in relative local currency prices over the following year. This finding that relative local currency prices appear to adjust to reduce deviations from Big Mac parity is consistent with the findings of Wei and Parsley (1995) who look at industry level prices.

Once again, a small- $\mathrm{T}$ bias of the slope is a potential problem that I address with a Monte Carlo experiment similar to the one described above. In this instance, the bias is considerably smaller (about -0.06 ) so that adjusting the fixed effects estimate of -0.24 by this estimate of the bias yields an adjusted slope of -0.18 . In this instance, the bias adjustment does not change the conclusions from the estimates in an important way.

\section{Concluding Remarks}

In this paper I examine the dynamics of deviations from Big Mac parity. In addition to asking if observed deviations from Big Mac parity are permanent or transitory, I examine the adjustment toward parity. In particular I ask if observing an overvalued currency according to the hamburger standard (a high U.S. dollar price of a Big Mac) allows one to forecast a subsequent depreciation of the currency and/or a subsequent decline in the relative local currency price of Big Macs.

The evidence points to three main conclusions. First, deviations from Big Mac parity are temporary rather than permanent. The half-life of deviations from Big Mac parity appear to be about 1 year, which is considerably shorter than estimates of the half-life of deviations from 
purchasing power parity ( $4-5$ years) that are reported in the literature. This estimated half life and the corresponding rate of convergence to Big Mac parity must be interpreted cautiously. The estimates are derived after allowing for non-zero currency-specific average deviations. These average deviations vary substantially across the countries in the sample and are frequently quite large. The evidence thus suggests that there are significant deviations from absolute Big Mac parity, but that once estimates of these constant deviations are removed from the data, convergence to constant-adjusted parity is quite rapid.

Second, deviations from Big Mac parity appear to provide useful information for forecasting exchange rates. After accounting for currency-specific constants, a 10 percent undervaluation according the hamburger standard in one year is associated with a 3.5 percent appreciation over the following year. Third, deviations from Big Mac parity do seem to be helpful in forecasting relative local currency prices. When the U.S. dollar price of Big Macs is high in a country, the relative local currency price of Big Macs in that country is likely to fall during the following year.

It would be cowardly not to offer hamburger standard forecasts of next April's exchange rates. Based on the April 1996 deviations from Big Mac parity (after adjusting for time and currency effects) and the bias-adjusted slope of 0.35 , the forecasts clearly point to a stronger dollar. The largest predicted moves are appreciations of the dollar of 13 percent against the yen and nearly 8 percent against the DM and the Belgian franc. The full set of forecasts is below. But, as the Economist warned in the initial Big Mac survey, "caveat hamburger." 
Hamburger Standard Forecasts of Exchange Rates

Actual Forecast

Country

April $1996 \quad$ April 1997

Australia

1.27

Belgium

31.20

1.29

Britain

1.51

33.76

Canada

1.36

1.47

Denmark

5.85

1.35

France

5.13

6.22

Germany

1.52

5.38

Holland

1.70

1.64

Hong Kong

7.74

1.81

Italy

1551.00

7.89

Japan

107.00

1490.52

Spain

126.00

121.55

Sweden

6.71

126.36

6.63 


\section{References}

Chamberlain, Gary (1984), "Panel Data," in Z. Griliches and M. Intrilligator, eds, Handbook of Econometrics, Vol. II, Amsterdam: North Holland, 1247-1318.

Dickey, David A. And Wayne A. Fuller (1979), "Distribution of the Estimators for Autoregressive Time Series with a Unit Root," Journal of the American Statistical Association 74, pp. $427-431$.

Frankel, Jeffrey A. and Andrew K. Rose (1996), "A Panel Project on Purchasing Power Parity: Mean Reversion Within and Between Countries," Journal of International Economics 40, 209224.

Hall, Alastair (1994), "Testing for a Unit Root in Time Series with Pretest Data-Based Model Selection," Joumal of Business and Economic Statistics 12, pp. 461-470.

Im, Kyungso, M. Hashem Pesaran, and Yongcheol Shin (1995), "Testing for Unit Roots in Heterogeneous Panels," working paper, Department of Applied Economics, University of Cambridge, June 1995.

Kiviet, Jan F. (1995), "On Bias, Inconsistency, and Efficiency of Various Estimators in Dynamic Panel Data Models," Journal of Econometrics 68, pp. 53-78.

Lothian, James (1994), "Multi-Country Evidence on the Behavior of Purchasing Power Parity Under the Current Float," working paper, Fordham University.

Nickell, Stephen (1981), "Biases in Dynamic Models with Fixed Effects," Econometrica 49, 1417-1426.

Ng, Serena and Pierre Perron (1995), "Unit Root Tests in ARMA Models with Data-Dependent Methods for the Selection of the Truncation Lag," Journal of the American Statistical Association 90, pp.268-281.

Pakko, Michael R and Patricia S. Pollard (1996), "For Here of To Go: Purchasing Power Parity and the Big Mac," Federal Reserve Board of St. Louis, Review, January/February 1996.

Wei, Shang-Jin and David Parsley (1995), "Purchasing Power Dis-Parity During the Floating Rate Period: Exchange Rate Volatility, Trade Barriers, and Other Culprits," NBER working paper \#5032. 


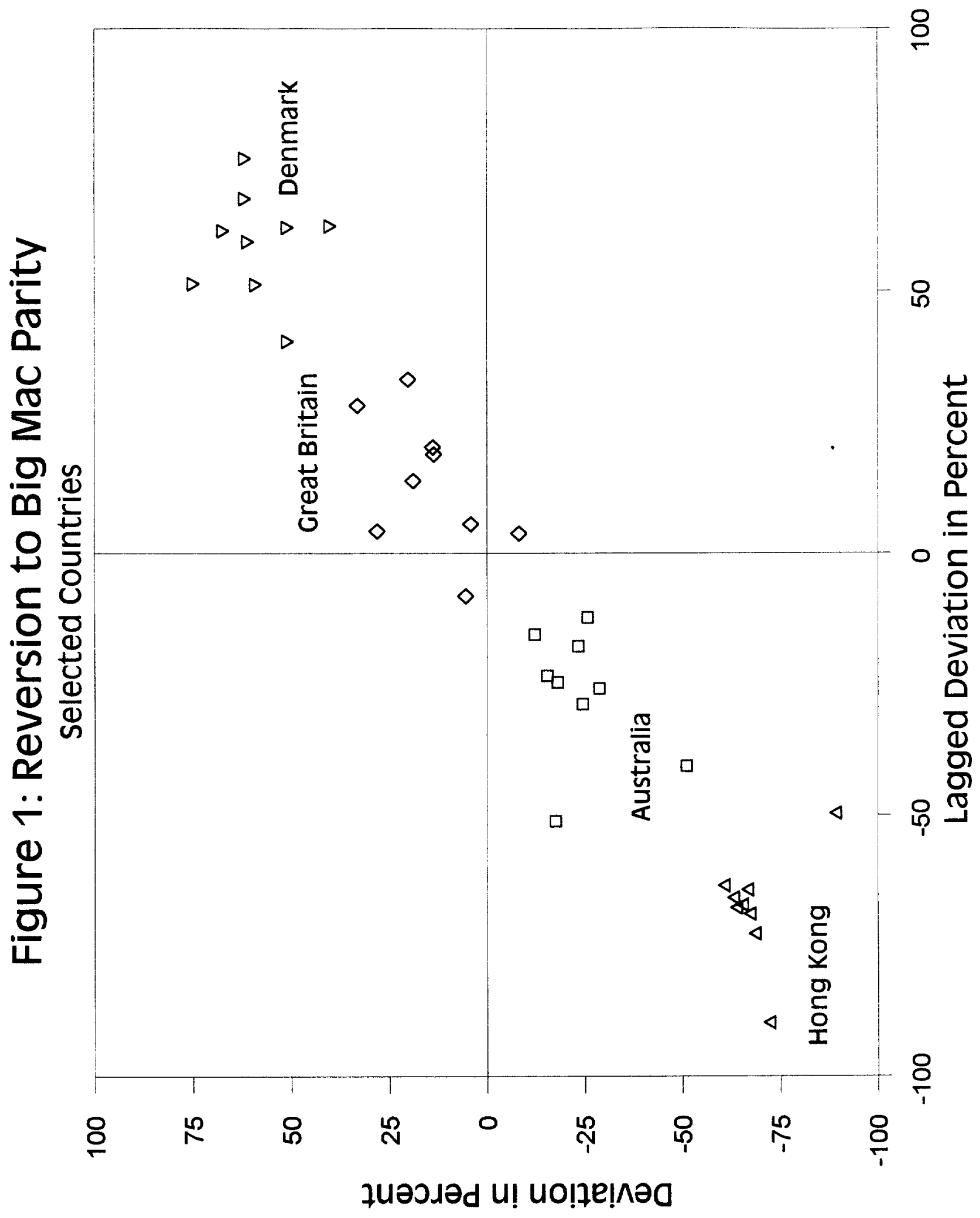


Table 1: Tests for Unit Roots in Deviations from Big Mac Parity, $\mathrm{q}_{\mathrm{i}, \mathrm{t}}=\ln \left(\mathrm{EBMP}_{\mathrm{i}, \mathrm{t}} / \mathrm{E}_{\mathrm{i}, \mathrm{t}}\right)$

$$
\Delta q_{i, t}=\theta_{i}+\left(\rho_{i}-1\right) q_{i, t-1}+\sum_{j=1}^{k_{i}} \gamma_{i j} \Delta q_{i, t-j}+v_{i, t}
$$

\begin{tabular}{lccccc} 
Country & $\overline{\mathrm{q}}_{\mathrm{i}}$ & $\hat{\theta}_{\mathrm{i}}$ & $\hat{\mathrm{\rho}}_{\mathrm{i}}$ & ADF Test & $\mathrm{k}_{\mathrm{i}}$ \\
\hline Australia & -0.257 & $\begin{array}{c}-0.160 \\
(0.096)\end{array}$ & $\begin{array}{c}(0.303 \\
(0.330)\end{array}$ & -2.112 & 0 \\
Belgium & & & & \\
& 0.302 & 0.175 & 0.412 & -1.674 & 0
\end{tabular}

\begin{tabular}{|c|c|c|c|c|c|}
\hline Great Britian & 0.134 & $\begin{array}{c}0.072 \\
(0.055)\end{array}$ & $\begin{array}{c}0.539 \\
(0.302)\end{array}$ & -1.529 & 0 \\
\hline Canada & -0.125 & $\begin{array}{l}-0.089 \\
(0.060)\end{array}$ & $\begin{array}{c}0.251 \\
(0.363)\end{array}$ & -2.063 & 0 \\
\hline Denmark & 0.595 & $\begin{array}{c}0.569 \\
(0.226)\end{array}$ & $\begin{array}{c}0.038 \\
(0.377)\end{array}$ & -2.549 & 0 \\
\hline France & 0.384 & $\begin{array}{c}0.484 \\
(0.105)\end{array}$ & $\begin{array}{l}-0.306 \\
(0.266)\end{array}$ & -4.917 & 0 \\
\hline Germany & 0.209 & $\begin{array}{c}0.168 \\
(0.084)\end{array}$ & $\begin{array}{c}0.150 \\
(0.377)\end{array}$ & -2.256 & 0 \\
\hline Holland & 0.251 & $\begin{array}{c}0.204 \\
(0.098)\end{array}$ & $\begin{array}{c}0.181 \\
(0.379)\end{array}$ & -2.160 & 0 \\
\hline Hong Kong & -0.671 & $\begin{array}{l}-0.882 \\
(0.196)\end{array}$ & $\begin{array}{l}-0.284 \\
(0.286)\end{array}$ & -4.486 & 0 \\
\hline Italy & 0.254 & $\begin{array}{c}0.247 \\
(0.091)\end{array}$ & $\begin{array}{l}-0.051 \\
(0.231)\end{array}$ & -3.275 & 0 \\
\hline Japan & 0.323 & $\begin{array}{c}0.278 \\
(0.154)\end{array}$ & $\begin{array}{c}0.104 \\
(0.398)\end{array}$ & -2.249 & 0 \\
\hline Spain & 0.215 & $\begin{array}{c}0.132 \\
(0.083)\end{array}$ & $\begin{array}{c}0.392 \\
(0.347)\end{array}$ & -4.913 & 2 \\
\hline Sweden & 0.473 & $\begin{array}{c}0.270 \\
(0.162)\end{array}$ & $\begin{array}{c}0.448 \\
(0.332)\end{array}$ & -1.663 & 0 \\
\hline
\end{tabular}

Im, Pesaran, Shin Test $\quad-3.898$

Im, Pesaran, Shin Test, Common Time Dummies $\quad-4.063$ 
Table 2: Pooled Estimates of the Rate of Convergence to Big Mac Parity $\ln \left(\frac{\mathrm{EBMP}_{\mathrm{i}, \mathrm{t}}}{\mathrm{E}_{\mathrm{i}, \mathrm{t}}}\right)=\theta_{\mathrm{i}}+\lambda_{\mathrm{t}}+\rho \ln \left(\frac{\mathrm{EBMP}_{\mathrm{i}, \mathrm{t}-1}}{\mathrm{E}_{\mathrm{i}, \mathrm{t}}}\right)+u_{\mathrm{i}, \mathrm{t}}$

Pooled Estimate

$\begin{array}{cc}\hat{\rho} \text { OLS } & \hat{\rho} \text { GLS } \\ 0.904 & 0.907 \\ (0.042) & (0.037)\end{array}$

Time Dummies Only

$\left(\theta_{\mathrm{i}}=\theta\right)$

$0.948 \quad 0.968$

$(0.028)$

(0.022)

Fixed Effects

0.276

0.242

(Time and Currency Dummies)

(0.121)

(0.079)

Table 3: Predicting Exchange Rate and Relative Local Currency Price Changes
A. $\quad \ln \left(\frac{E_{i, t}}{E_{i, t-1}}\right)=\delta_{i}+\varphi_{t}+\beta \ln \left(\frac{E B M P_{i, t-1}}{E_{i, t-1}}\right)+v_{i, t}$
Pooled Estimate
$\hat{\beta}$ OLS
$\hat{\beta}$ GLS
$\left(\delta_{\mathrm{i}}=\delta, \varphi_{\mathrm{i}}=0\right)$
0.016
$(0.022)$
$-0.000$
Time Dummies Only
0.020
$(0.007)$
$\left(\delta_{i}=\delta\right)$
$(0.021)$
0.012
$(0.020)$
Fixed Effects
0.483
0.523
(Time and Currency Dummies)
$(0.077)$
(0.068)

B. $\quad \ln \left(\frac{\text { EBMP }_{i, t}}{\operatorname{EBMP}_{i, t-1}}\right)=\mu_{i}+\psi_{t}+\pi \ln \left(\frac{\text { EBMP }_{i, t-1}}{E_{i, t-1}}\right)+\eta_{i, t}$

Pooled Estimate

$\left(\mu_{\mathrm{i}}=\mu, \Psi_{\mathrm{t}}=0\right)$

Time Dummies Only

$\left(\mu_{i}=\mu\right)$

Fixed Effects

(Time and Currency Dummies)

$$
\begin{array}{ll}
\hat{\pi} \text { OLS } & \hat{\pi} \text { GLS } \\
-0.080 & -0.074 \\
(0.039) & (0.039)
\end{array}
$$

$\begin{array}{ll}-0.032 & -0.029\end{array}$

$(0.015) \quad(0.011)$

$\begin{array}{ll}-0.241 & -0.179 \\ (0.074) & (0.044)\end{array}$

